\title{
Sales Driven Company
}

Viele Unternehmen haben sich in den letzten Jahren mit der Verbesserung der Kundenorientierung beschäftigt. Es ist vielfach belegt worden, dass dies zum Erfolg des Unternehmens beiträgt. Die alleinige Orientierung am Kunden und seinen Bedürfnissen reicht jedoch nach unseren Erkenntnissen nicht aus. Wenn man sich kontinuierlich an den Ergebnissen der Kundenzufriedenheitsstudien und den Fortschritten der Mitarbeiter orientiert, werden Unternehmen zu passiv und geben die aktive Koordination der Kundenbeziehungen aus den Händen.

Daher propagieren wir zur Kundenorientierung die Verkaufsorientierung der Unternehmen im Sinne einer Sales Driven Company. Dabei geht es nicht etwa um eine Rückkehr zu den alten Konzepten des „Hardselling“, also Verkaufen um jeden Preis, sondern um professionelle Verkaufsorientierung, die dem Kunden und dem eigenen Unternehmen dient.

In einer Sales Driven Company wird der Verkauf zum Wettbewerbsvorteil oder strategischen Erfolgsfaktor. Vertriebsorientierte Unternehmen - oder Sales Driven Companies, wie wir sie gerne nennen - schätzen ihre Verkaufsmannschaft und die Mitarbeiter identifizieren sich mit der Funktion und unterstützen diese. Sales Driven Companies entwickeln ihre Kompetenzen im Verkauf systematisch und schaffen interne Rahmenbedingungen, die Verkaufsorientierung fördern. Die Verkaufsorientierung in diesem Sinne basiert auf Kundenorientierung, aber erweitert diese um ein proaktives Vorgehen des Anbieters.

Das Titelbild des Zugs mit der Vertriebs-Lokomotive, welche die anderen Unternehmensteile mitzieht, drückt dieses Unternehmensverständnis metaphorisch aus. Ein erfolgreicher Vertrieb als loco motivus (lat. von der Stelle bewegend) wirkt als Motor für das Unternehmen.

In dieser Ausgabe wird dieser Mehrwert, der durch den Vertrieb geschaffen wird, von Wissenschaftlern und Praktikern auf drei Ebenen erörtert. Im ersten Teil „Verkauf“ wird auf die notwendige Vertriebsorientierung des Unternehmens eingegangen, der Teil „Kunden“ bezieht sich auf die hierfür notwendige Kundenorientierung und der letzte Teil „Unternehmen“ beleuchtet die organisatorischen Voraussetzungen der Vertriebsorientierung.

Wir danken den Autoren und Reviewern herzlich für ihre wertvollen Impulse und wünschen Ihnen, liebe Leserinnen und Leser, viele neue Einsichten und Freude bei der Lektüre. Über Rückmeldungen freuen wir uns sehr. Für eine vertiefte Auseinandersetzung mit dem Thema bieten wir auch das gleichnamige Gemeinschaftsprogramm mit elf namhaften Partnerunternehmen an und laden Sie für weitergehende Informationen diesbezüglich herzlich auf unsere Website www.salesdrivencompany.com ein.
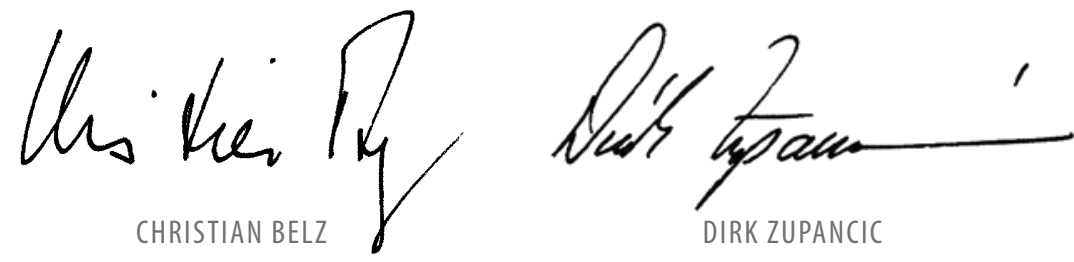

\section{Prof. Dr. Christian Belz}

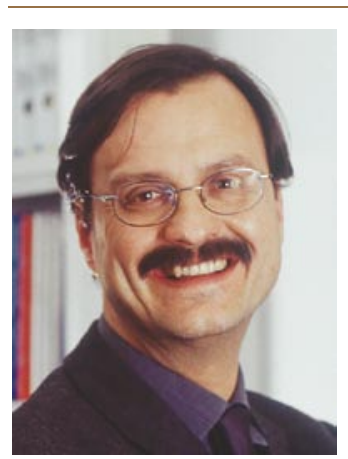

Ordinarius für Marketing an der Universität St. Gallen und Geschäftsführer des Instituts für Marketing sowie Mitbegründer und -herausgeber der Marketing Review St. Gallen

E-Mail: christian.belz@unisg.ch

\section{Prof. Dr. Dirk Zupancic}

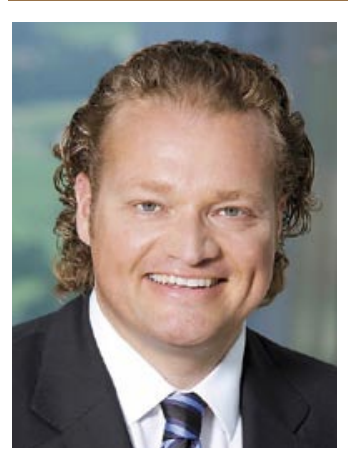

CEO/Managing Dean der privaten German Graduate School of Management and Law in Heilbronn (D) sowie Dozent und Leiter Business to Business Marketing und Verkauf an der Universität St. Gallen.

E-Mail: dirk.zupancic@unisg.ch 